\title{
A CICATRIZ DA CESÁREA (IN) DESEJADA: marca que significa corpos e mulheres na atualidade
}

\author{
THE DESIRED (IN) CESAREAN SCAR: \\ brand that means bodies and women today
}

Rosamaria Giatti Carneiro*

\begin{abstract}
Resumo
Cresce no Brasil o número de mulheres adeptas do parto "mais natural" e/ou parto humanizado. Nesse universo, de camadas médias, nega-se a cesárea como método mais seguro de nascer e vigora a ideia de que o parto sem as rotineiras intervenções médicas pode ser libertário e transformador. Mas nem todas essas mulheres alcançam a experiência desejada, experimentando a cirurgia como via de nascimento. De minha incursão nesses grupos de mulheres, presenciais (CARNEIRO, 2015) e mais recentemente virtuais, percebo que a cicatriz deixada por esse procedimento se faz corporalidade e cultura, na esteira do pensado como embodiment (CSORDAS, 2008; MALUF, 2001). Enquanto "marca" física e emocional pode simbolizar trauma, fracasso de um projeto ou, então, avessamente, o motor para uma outra experiência. Algumas dessas mulheres viveram uma depressão pós-parto e esconderam-se de/a si mesmas; outras corporificaram a denúncia da violência em projetos imagéticos pessoais; enquanto outras seguiram depois, em outra gestação, em busca do Vaginal Birth After Cesarian Section (VBAC). Para pensar sobre os significados dessa cicatriz, inspirada em Das (2007), partirei de seus corpos entrecortados, a fim de refletir sobre sofrimento e pessoa.
\end{abstract}

Palavras-chave: Cesárea. Marcas. Sofrimento. Pessoa.

\begin{abstract}
The number of women who are more "natural" and / or humanized labor is growing in Brazil. In this medium-sized universe, cesarean delivery is denied as the safest method of birth, and the idea that labor, without routine medical interventions, can be libertarian and transformative, holds true. But not all of these women achieve the desired experience and experience surgery as the way of birth. From my foray into these groups of women, face-to-face (CARNEIRO, 2015) and more recently virtual, I realize that the scar left by this procedure becomes corporeality and culture, in the wake of the idea of embodiment (CSORDAS, 2008 and MALUF, 2001). While physical and emotional "branding" can symbolize trauma, failure of one project or, then, averse, engine for another experience. Some of these women experienced postpartum depression and hid from themselves; others embodied the denunciation of violence in
\end{abstract}

\footnotetext{
* Professora da Universidade de Brasília/Brasil, doutora em Ciências Sociais pelo Instituto de Filosofia e Ciências Humanas da Unicamp/Brasil. E-mail: rosacarneiro@unb.br
} 
personal imagery projects; while others followed in another gestation in search of the Vaginal Birth After Cesarian Section (VBAC). To think about the meanings of this scar, inspired by Das (2007), I will depart from their broken bodies in order to reflect on suffering and the person.

Keywords: Cesarian. Scars. Suffering. Person.

\section{Notas Introdutórias: fontes e contextos}

Este artigo se dispõe a refletir sobre os significados da cesárea e de sua cicatriz para mulheres que a viveram, mas não a desejavam. Debruça-se mais especificamente sobre as estórias de parto e de pós-parto de mulheres que queriam um parto natural, sem intervenções médicas e farmacológicas, mas que, por uma série de questões, experimentaram o seu contrário na cirurgia. São mulheres, em sua maioria, de camadas médias e inseridas no movimento do parto humanizado (CARNEIRO, 2015). Para discutir se e de que modos a cicatriz e a cirurgia lhes dão outros contornos de corpo e de pessoa, explorarei distintas fontes de campo: trechos e passagens de minha etnografia entre mulheres paulistas que buscaram um parto mais natural entre 2007-2011 (CARNEIRO, 2015); posts de redes sociais de mulheres que viveram a cesárea, colhidos intermitentemente nos últimos 2 anos (2015-2017) em plataformas a serem citadas, e, por fim, teoria antropológica sobre corpo e/ou produções imagéticas que dialoguem ou explorem o sofrimento e a dor decorrentes da cirurgia, desde que provientes de mulheres que a sentiram.

Desse modo, diferentes e múltiplas serão as fontes consideradas. Todas, no entanto, no sentido de pensar sobre os significados da cesárea, de suas marcas no corpo e desenho de pessoa dessas mulheres. Elas têm temporalidades diferentes: a etnografia foi escrita entre 2007-2011. Estive em grupos de preparo para o parto e em partos entre as adeptas de outros modos de parir por quase 3 anos (CARNEIRO, 2015), tratando de mapear leituras de corpo, pessoa e sexualidade. A coleta de posts sobre os significados da cicatriz e da cirurgia nas redes e grupos virtuais aconteceu mais recentemente a partir do surgimento de casos como esses, pouco frequentes até então; enquanto os textos têm por base a atemporalidade dada sua potência analítica. Penso, entretanto, que essa diversidade só adensa o argumento, explorando tempos e espaços diversos; ainda que, novamente, importe ressaltar, toda a discussão a ser travada tenha por solo uma parcela das mulheres brasileiras: as de camadas médias e adeptas do parto mais natural (CARNEIRO, 2015) que experimentaram uma cesárea indesejada, tanto no Brasil, como nos EUA e na Europa.

\section{Quem são e o que querem essas mulheres?}

Cresce no Brasil o número de adeptas do que tenho denominado de ideário do parto humanizado (CARNEIRO, 2015). Se nas décadas de 1980 e 1990, pudemos assistir a prevalência das cesarianas como modo mais seguro, rápido e indolor de nascer, com o advento das críticas ao modelo de obstetrícia, sobretudo, a partir dos anos 2000, passou a existir um movimento contracorrente. Tal reação passou a indagar o alto índice de cesáreas realizadas no país, o conjunto de intervenções 
desnecessárias no corpo feminino e do recém-nascido e as consequências de tais práticas no que tange à morbimortalidade materno-infantil. De início, esse coro reativo foi composto por profissionais de saúde, porém, pouco a pouco, foi engrossado por mulheres de camadas médias que buscavam um outro tipo de parto, diferente do "parto que corta" ou "não-parto". Nesse mesmo período, despontou a Rede de Humanização do Parto e do Nascimento(ReHuNa) ${ }^{1}$ e uma gama de grupos de preparo para o parto humanizado e listas virtuais de discussão sobre esse momento da vida das mulheres.

Tornou-se comum encontrar blogs que tematizam o parto e o pós-parto, imagens de parto, desabafos e críticas ao vivido por algumas mulheres, maternidade ativa e cesarianas indesejadas mais expressivamente na rede social Facebook ${ }^{2}$. Dessa forma, fala-se e escreve-se mais abertamente sobre o parir e o nascer entre as mulheres e casais de camadas médias e de centros urbanos e, talvez por isso, pesquisas sobre tais temas também tenham se tornado mais presentes como a da Fundação Perseu Abramo $(2010)^{3}$, que explorou a ideia de violência no parto e concluiu que a cada grupo de 4 mulheres, 1 declara ter vivido violência ao parir.

Entre as "adeptas do parto humanizado" vigora o desejo de um parto singular e não somente mais um parto "dentro do sistema", a saber, com as rotinas de atendimento padrão (CARNEIRO, 2015). Questionam, por essa razão e a título de exemplo, a cesariana agendada; os procedimentos de recepção do recém-nascido (aspiração, banho, colírio, vitamina $\mathrm{K}$, corte do cordão); os benefícios da episiotomia e do uso da analgesia peridural; criticam a falta de acolhimento nos hospitais e a separação da mulher de seus familiares e criança ao nascer. E assim, apontam para os limites e vícios de um olhar biomédico que estigmatiza o nascer e o parir, que o torna a priori perigoso e arriscado.

De forma bem geral, pois o cenário comporta todo o tipo de nuances, opera no Brasil atual a "cultura da cesárea agendada", geralmente, entre 37 e 40 semanas; sem sinais de trabalho de parto; com o objetivo de "evitar a dor" ou "o sofrimento" ao recém-nascido. A cesariana é uma cirurgia de médio porte que conta com anestesia epidural, lenta recuperação da mãe e de risco materno aumentado em termos de infecção e hemorragia pós-parto. Ou então, coexiste um modelo de "parto vaginal", alcunhado emicamente, de "parto frank" (cadernos de campo, 2008-2010), numa alusão a Frankestien, em que a mulher é submetida ao "efeito cascata" (CARNEIRO, 2015): chega ao hospital, se desfaz de todos os seus aparatos e adornos pessoais, usa a camisola branca para uniformizá-la, tem os pelos pubianos raspados e o intestino "limpo" por meio de uma sonda; recebe ocitocina (hormônio) na veia para aumentar as contrações uterinas, é proibida de andar durante o trabalho de parto e/ou assumir outras posturas de parto, recebe anestesia e, por vezes, tem a sua bolsa rompida

\footnotetext{
1 Organização da sociedade civil que desde 1993 vem atuando em forma de Rede em todo o Brasil. Ver: http://www.rehuna.org.br/.

2 Muitos desses grupos são "fechados", por isso não podem aqui ser mencionados, em razão de um pacto de confidencialidade.

3 Ver: <http://novo.fpabramo.org.br/content/violencia-no-parto-na-hora-de-fazer-nao-gritou>
} 
artificialmente; não suporta as dores e, assim, ou pare o bebê sem nenhum amparo e em tais condições. Ou ainda, quando pode, pede pela cirurgia por conta da agressão de todo esse processo.

Dessa forma, as mulheres que querem parir naturalmente dizem querer escapar desses modelos e, para isso, procuram informações, profissionais e alternativas de parto, como o parto domiciliar, por exemplo (CARNEIRO, 2015). $\mathrm{Na}$ etnografia realizada em grupos de adeptas do parto humanizado paulistas (CARNEIRO, 2015), percebi que antes de se consolidarem em um grupo com características muitos definidas, compõem um conjunto bastante heterogêneo em termos de estilo de vida, idade, religião, profissão, conjugalidade, razões de escolha do parto natural etc. Porém, em outros sentidos, se aproximam ao terem acesso e contarem com a internet como ferramenta de articulação; serem críticas em relação ao modelo médico vigente e adensarem as camadas médias, ainda que com múltiplas configurações econômicas.

Em síntese, perseguem uma experiência de parto que "seja sua" e não somente a de mais uma mulher, passando pelo procedimento que se tornou padrão no Brasil. Entendendo o corpo feminino antes como possibilidade e menos como fragilidade e perigo, como ao que parece pensar a obstetrícia moderna desde o seu início (CARNEIRO, 2015).

\section{A cesárea nessa roda de mulheres: quando a experiência é a indesejada}

Vale refletir sobre como a cesárea, justamente o que se busca evitar, tem sido compreendida nesse universo feminino. Enquanto procedimento do qual nenhuma mulher estaria isenta, já que pode ser necessária para salvar vidas, pouco parece ser pautado nas reuniões de preparo para o parto natural. Segundo Joana, uma doula e coordenadora de um dos grupos de preparo para o parto por mim etnografados, "pouco se fala sobre a cesárea nas reuniões" (notas de campo, 2009). E "quando o tema é esse, o encontro parece não fluir" (notas do caderno de campo, 2010). Nesse sentido, a cirurgia, a príncipio, figura como um "tabu", algo a ser negado e que as mulheres custam a trabalhar como algo que pode vir a acontecer. A cesárea, assim, seria "o não dito", aquilo que se nega, mas que tampouco se aceita.

Em outros registros, quando acontece, ao menos do que pude depreender de meu trabalho com mulheres paulistas adeptas de outros modos de parir, a cesárea vem significada como "trauma", "tristeza" e "indignação", tanto para aquelas que já passaram pela cirurgia em uma primeira gestação, quanto as que a negaram veementemente como melhor modo de parir (CARNEIRO, 2015). Para algumas dessas mulheres, a cesárea representou uma expropriação, "o roubo de uma experiência" (CARNEIRO, 2015, p.154). Nesse grupo, concentram-se as mulheres que se decepcionaram com seus médicos e consigo mesmas por não terem evitado o corte abdominal. E que, em situações extremas, mas bastante comuns, vivenciaram uma depressão pós-parto, um baby blues. Ou dificuldade de relação com os filhos etc.

Mas pode ainda a cesárea representar "o corte", "a ferida na alma" e a fragmentação da pessoa. Nesse registro, a incisão além de física parece ser também 
emocional. Nesses casos, algumas mulheres se isolam, deixam de reconhecer a si mesmas, afastam-se do movimento de humanização do parto e ou, por muitas vezes, ao contrário, permanecem em silêncio. E outras que, bem diferentemente, fazem dessa desilusão o motor para o ativismo por outras mulheres (CARNEIRO, 2015) ou para uma outra experiência pessoal, tornando-se doulas, obstetrizes, parteiras. $\mathrm{Ou}$ então, perseguindo um VABC.

\section{“Eu caí numa cesárea”: a segmentação do grupo}

Eu já era enfermeira há 5 anos e me informei muito durante a gravidez, participava de grupos no Orkut, e mesmo assim caí numa "desnecesárea" quando completei 41 semanas, por 'falta de dilatação, bebê podia entrar em sofrimento a qualquer momento, a placenta podia envelhecer de repente, se entrasse em trabalho de parto no meio da semana poderia não ter vaga no hospital que escolhi etc. Enfim, caí na faca com 41 semanas e depois que digeri fui atrás de informação, virei ativista e me especializei para tentar fazer diferença na vida de outras mulheres, para que não passem pelo que passei (ANJOS, 2015b - grifos em negrito nossos).

É comum em rodas de parto escutarmos depoimentos pessoais. Entre os principais, quase sempre aparecem os relatos de partos em casa bem-sucedidos, mas também, entre um ou outro, aparece uma mulher com as seguintes palavras: "eu tentei de tudo, me preparei, mas caí numa cesárea”. Ou, "vivi uma desnecesárea”. Ou ainda, desoladamente, "perdi para o sistema!", fazendo referência emicamente ao regime da cesariana regra de atenção no Brasil.

Esse "cair em uma cesárea" figura quase como cair numa armadilha. Ou então, sugere um fracasso, uma espécie de "nadar contra a maré, mas morrer na praia". Interessante é que tais narrativas despontam depois de já aquecida a discussão nas reuniões dos grupos. Raramente abrem a roda de relatos e, para as que viveram a cesárea, aparecem, muitas vezes, como motivo de tristeza ou vergonha. Da cicatriz, então, ou pouco se fala, ou aparece como marca que fragmenta, corta e mutila a pessoa.

“Fiz todo o possível, mas no meu caso não deu .... Algumas dessas mulheres nem mesmo voltam aos grupos de preparo para o parto de origem para relatarem as suas experiências e outras tampouco escrevem em seus blogs. Muitas preferem o silêncio e o isolamento. E assim entre o desejo, o preparo para o parto em casa e o desfecho final aparece um hiato. Um hiato, ao que parece, de ser difícil de ser simbolizado.

Posto dessa maneira, no grupo maior das adeptas do parto humanizado, encontra-se hoje um grupo menor: o das mulheres que queriam um parto humanizado, mas vivenciaram uma cesárea. Nesse, entretanto, e por sua vez, pôde-se perceber uma subdivisão: o das mulheres que "caíram numa cesárea" (buscaram o parto natural, mas nem sempre passaram pelo trabalho de parto) e as mulheres que passaram por uma "transferência", termo nativo que significa a migração de um parto em casa para o hospital, com ou em trabalho de parto, e 
que pode terminar na denominada "cesárea intraparto". A diferença entre ambos os grupos é fundamentalmente a vivência do trabalho de parto antes do desfecho final. Diferencial esse, contudo, que, como se verá, pode pesar na simbolização do vivido, posto que, para algumas mulheres que vivenciaram o trabalho de parto, a cesárea final pode ser compreendida como necessária. Enquanto que, para as mulheres que nem experimentaram as contrações, pode ser mais difícil a narrativa e a compreensão do vivido. Nessa chave, "ter tentado até o fim" aparece como justificativa da aceitação do procedimento cirúrgico e de uma "cesárea necessária" ou "realmente necessária" como se pode ler nos grupos e listas virtuais e presenciais.

[...] Me fica um pingo de frustração por não ter parido minha filha. Queria sentir o expulsivo, queria sentir ela saindo de mim através do nosso próprio esforço conjunto, queria pegá-la e acolhê-la.

[...] Sei que o trabalho de parto não foi em vão e isso me acalenta. Nenhuma "gota" de ocitocina (o hormônio do amor) é desperdiçada (ALAYA, 2013).-

Para além disso, ter vivido o trabalho de parto, para esse grupo de mulheres, figura também como respeito ao momento de o bebê nascer, a espera vivida e o tempo fisiológico, tão valorizado nesse campo. Muitas mulheres consideram ser fundamental para o vínculo com a criança e para a "descida do leite".

Certamente a ocitocina que liberamos durante o trabalho de parto ajudou no nosso vínculo, ajudou na decida do leite, a estarmos preparadas. No segundo dia no hospital eu já tinha leite -- é por que passei pelo trabalho de parto! Minha filha nasceu quando ela estava pronta, quando ela quis, não foi arrancada de mim antes da hora. Não me arrependo do que vivi e do que planejei, e faria tudo outra vez (ALAYA, 2013 - grifos nossos).

Por fim, não é incomum que a cesariana vivida por esses dois grupos de mulheres termine significada pelos sentimentos de "culpa" ou de "fracasso" como se o corpo daquela mulher não tivesse sido capaz de parir. Falta de coragem, problema emocional ou corporal, falta de persistência são algumas das emoções e percepções que, em seguida, parecem circular entre tais mulheres. Ou então, para algumas, quando vivido o trabalho de parto (ou não necessariamente), a postura pode ser outra, como por exemplo:

Decidi não cultivar sentimentos de culpa ou fracasso. Quando uma mulher consegue parir, as pessoas a congratulam com adjetivos positivos sobre como ela é forte, empoderada, parideira... Teria sido eu fraca? Teria meu corpo falhado? Eu tinha algum defeito que me impediu de parir? Tinha alguma trava emocional que não soube identificar? Toda minha experiência era inválida porque terminei em cesárea? Não! Eu não ia entrar nessa armadilha emocional (ALAYA, 2013 - grifos nossos). 


\section{HomeBirth Cesarean in USA: a new category to think}

No Brasil, ao que parece, dada a novidade do ideário do parto humanizado e do parto em casa urbano e contemporâneo, pouco ainda se discorre sobre as trajetórias de mulheres que buscaram um parto em casa, mas tiveram de migrar para o hospital e passar por uma cesárea. Nos Estados Unidos, entretanto, a partir de 2012, tanto o assunto quanto o grupo ganharam espaço e um termo especifico para nomeá-lo: Homebirth Cesarean. Expressão usada entre e para as mulheres que buscaram parir em casa, mas que, por muitas razões, tiveram de ir para o hospital e vivenciar a cirurgia. O termo surgiu em 2011 por iniciativa de uma estudante de midwife (parteiras), Courtney Jareki, que teve de ser transferida para o hospital por conta da presença de mecônio (fezes do bebê no interior do útero), depois de quase 50 horas de trabalho de parto ${ }^{4}$.

Jareki inicia o grupo de apoio para mulheres nessa mesma situação depois de ter vivido um difícil pós-parto e ter contado com o apoio de suas parteiras para a elaboração do processo. Inicialmente, a proposta ocupava uma página no Facebook, mas, em seguida, surgiu o blog e depois um livro, que conta com um capítulo específico sobre a necessidade de transferência para os hospitais. Nele, Jareki chama a atenção para a necessidade dos próprios profissionais preparem as mulheres para essa possibilidade e ainda no pré-parto, mas também a si mesmos enquanto profissionais, pelo seguinte motivo,

[... ] mãe no hospital abandona controle de seu trabalho, seu corpo, seu bebê, e agora ela deve lidar com inúmeras intervenções. Ela pode se sentir incapaz de parar o trem de loucura que ela percebe que seu nascimento está se tornando, e ela pode renunciar a sua tomada de decisão, de autonomia. Além disso, a equipe do hospital raramente percebe e reconhece a dor mental, espiritual e emocional de um transporte. Muitas vezes eles simplesmente veem uma mãe homebirth que pode ser difícil de trabalhar, porque ela está protestando intervenções. Mas quando o pessoal do hospital reconhece a angústia do transporte e outras escolhas de cuidado, sempre que possível, a mãe pode sentir que mantém a sua dignidade e o seu direito à autodeterminação (LOWE, 2015). ${ }^{5}$

\footnotetext{
4 Veja o depoimento completo em: <https://www.youtube.com/watch?v=J11DkcMvo8A $>$.

5 Tradução da autora: “... mother in the hospital relinquishes control of her labor, her body, her baby, and now she must contend with numerous interventions. She may feel unable to stop the train of madness that she perceives her birth is becoming, and she may surrender her decision-making autonomy. Furthermore, hospital staff rarely recognize and acknowledge the mental, spiritual, and emotional pain of a transport. Often they simply see a homebirth mother who might be difficult to work with because she is protesting interventions. But when hospital personnel do recognize the distress of transport and other choices in her care whenever possible, the mother can feel that she maintains her dignity and her right to self-determination."
} 
Esse grupo conta atualmente com mais de 3000 participantes e Jareki desenvolve também um trabalho de informação e de cuidados (oficinas vivenciais) com mulheres que vivenciaram uma cesárea indesejada. Em seu blog, encontra-se ainda bibliografia especializada, artigos, mídias e livros sobre o tema; espaço em que também circulam notícias de eventos e agenda de suporte para mulheres e famílias. O escopo maior parece ser evitar a depressão pós-parto, escutar tais mulheres e suas estórias e evitar problemas de vinculação com o bebê. E talvez, ainda mais, ou sobretudo, apontar para a existência desse grupo de mulheres.

\section{Corpos marcados, sofrimento e trauma}

Eu tremia muito de reação da anestesia raquidiana. Tremia de frio e tremia da descarga de adrenalina (assim me disse o anestesista que foi muito gentil me tranquilizando). Senti o bisturi elétrico traçando linhas no meu corpo, senti o cheiro da minha carne, a Rosana me abria ... (ALAYA, 2013).

"Eu senti o cheiro da minha carne”. Ou, “[...] era mais um corpo indo ser cortado, era mais uma". Frases como essas desabafam sentimentos de sofrimento e, em certas situações, de trauma. Nesses casos, salientado pela cicatriz deixada pela cirurgia. Nos relatos virtuais e presenciais, as palavras nos falam antes do corpo, mas que é também pessoa. Corpos cortados, pernas adormecidas, líquidos escorrendo pelas costas, manipulação no ventre para a retirada do bebê. Curioso é que são sensações corporais, mas também imagéticas, já que "fisiologicamente" as mulheres estão anestesiadas e "nada poderiam sentir". Talvez por conta desse "não sentir nada" ser exatamente a sensação do pesar e de tristeza, paradoxalmente, é sentido. Elabora-se pelo que se não sentiu. Enlutase pelo não sentido. Mas ao mesmo tempo as palavras transparecem pura sensação, algo a ser pensado a partir da ideia de que o corpo é cultura e faz cultura (CSORDAS, 2008) e de que entre natureza e cultura (corpo/mente) existe muito mais relação, invenção e imbricamento do que a priori ou antecedência (WAGNER, 2010).

Dessa forma, como se viu no relato anterior, não sentir o período expulsivo do bebê, a dor e o parto vaginal é justamente o motivo do sofrimento. Nesse registro, deixar o corpo para outrem manipular é a razão do descontentamento e, por vezes, do trauma. Da cirurgia vivida certamente restam as lembranças (das quais pode-se, ou não, querer falar), mas um registro corporal e imagético: a cicatriz da cirurgia. Esta fala por si só e parece poder revelar algo que nem mesmo aquela que a porta gostaria de revelar.

Foi horrível. Meu marido filmou. Não consigo assistir sem chorar, mal consigo ver. Doeu muito. Doeu o pós-operatório, doeu não ser respeitada, dói a cicatriz até hoje, não no corpo, mas a que ficou na alma. O luto do parto roubado (ANJOS, 2015a).

Tais registros corporais podem, contrariamente, inspirar a verborragia. Como sustentado anteriormente, o corpo fala, o corpo faz falar e simbolizar, cria cultura. Por isso, mesmo nos casos em que cala, também fala. Para Venna Das, 
antropóloga indiana que reflete a partir dos testemunhos e cotidiano de indianas que sobreviveram à partição da Índia,

através de complexas transações entre corpo e linguagem, elas foram capazes de dar voz e de mostrar os prejuízos causados a elas e também de dar testemunho do dano causado ao tecido social como um todo - o ataque era à ideia mesma de que grupos diferentes fossem capazes de habitar o mundo conjuntamente (DAS, 2011, p. 11).

Mas toda a postura do corpo, ao oferecer critérios externos pelos quais os outros possam ler o "interno", é um movimento cultural importante que está mergulhado, neste caso, na gramática da viuvez na sociedade indiana. Inclinome a dizer que o corpo se torna quase expressivo demais para carregar (DAS, 2011, p. 24).

No caso das mulheres que viveram uma cesariana indesejada, o corpo cortado, por vezes, também se torna expressivo demais para carregar e outros caminhos são trilhados no sentido de se retornar ao cotidiano, termo também pensado por Das. Eis então, por um lado, a importância do testemunhar e do narrar o vivido para dar vazão à dor e se anunciar enquanto pessoa a partir do extraordinário (cesariana indesejada).

Justamente com esse foco, existe um projeto fotográfico de Alvarez-Errecalde, uma fotógrafa argentina radicada em Barcelona que ilustra as marcas corporais deixadas por cesarianas indesejadas de um conjunto de mulheres espanholas. Cesárea, más allá de la herida (ALVAREZ-ERRECALDE, 2010) conjuga cicatrizes e textos/palavras das próprias mulheres sobre o experimentado. Nas fotos, as mulheres assumem posições, gestos e trejeitos como os que se veem abaixo, acolhendo a marca no corpo e expondo sua intimidade.

Figura 1 - Capa do livro cesárea más allá de la herida

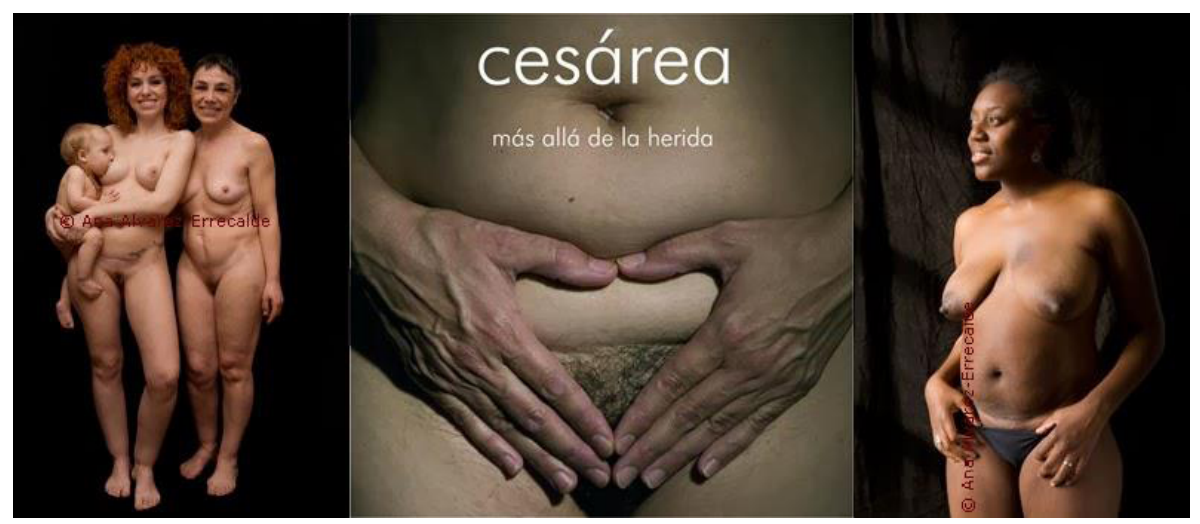

Fonte: http://alvarezerrecalde.com/portfolio/cesarea-mas-alla-de-la-herida/ 
Se algumas imagens demonstram acolhimento e ressignificação, outras trazem à tona violência, cegueira e opressão como na imagem a seguir, que, em especial, parece nos remeter a um sofrimento e a uma sensação de expropriação dos próprios sentidos. De acordo com um vídeo disponível na internet ${ }^{6}$ que expõe o projeto, "a cesárea seja por alegria ou tristeza sempre deixa uma marca”. Mas, "a sociedade não permite que a mulher lamente a sua experiência”.

Figura 2 - Auto-retrato ${ }^{7}$

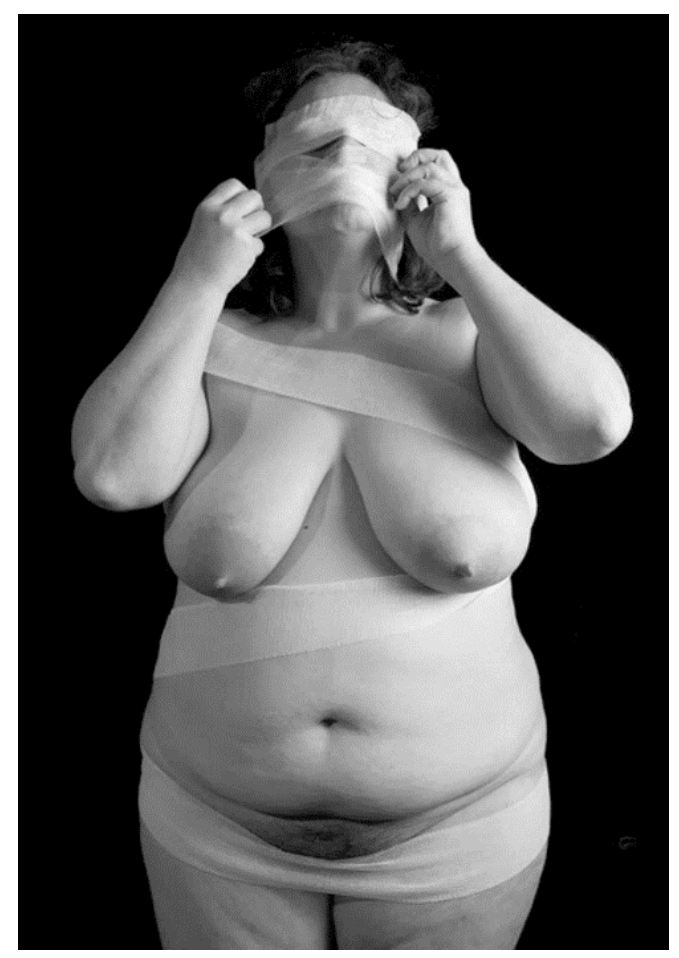

Fonte: http://alvarezerrecalde.com/portfolio/cesarea-mas-alla-de-la-herida/

Em certas situações, o testemunho carrega ainda uma dor latente. Em outras, já há um processo de ressignificação do ocorrido. A primeira imagem denota um acarinhamento com a cicatriz, enquanto que esta última e relatos como o que segue, arrastam a dificuldade de dizer-se e o sofrimento oriundo da experiência não desejada e simbolizada como trauma.

6 Veja o vídeo completo em: <http://mamikanguro.com/blog/cesarea-mas-alla-de-la-herida/>.

7 Em sua origem, esta imagem não possui título; o título aqui atribuído se restringe ao papel que ela desempenha neste texto. 
Fui pra cesárea. Me senti a pessoa mais incapaz do mundo, frágil. Achava que tinha alguma coisa errada comigo, e por que justo comigo? Tantas pessoas ao meu redor marcavam cesárea, e eu, que queria ter normal, não podia, porque tinha algo errado comigo... Me senti péssima mãe, pois a médica tinha dito que meu filho já não estava bem dentro de mim. Me senti um monstro fazendo mal para o meu próprio filho... Como eu poderia ser capaz? (ANJOS, 2015a).

Pelo que se nota atualmente, essas imagens de corpos e os respectivos processos de testemunho podem ser/aparecer como individuais ou coletivos, por meio de blogs e relatos individuais nas redes sociais. Mas também em grupos coletivos, fechados e abertos, virtuais ou presenciais que abordem a questão. A imagem e o relato que seguem, por exemplo, pertencem a um grupo de discussão virtual sobre cesariana indesejada, funcionando como uma espécie de símbolo ou totem que aproxima mulheres que sofreram o mesmo trauma e que, no coletivo, se reconhecem e buscam por outros significados para a experiência. Dela se pode depreender cores e leveza, uma mulher com ventre cortado, uma cicatriz, lado a lado com seu companheiro e bebê, em uma cena de profundo acolhimento. Longe de retratar dor e opressão, traz à tona um processo de "aceitação" da experiência vivida, ainda que indesejada e, desse modo, fala dessas mulheres de outro modo que não o das mulheres que sofreram violência.

Figura 3 - Cesarean 2

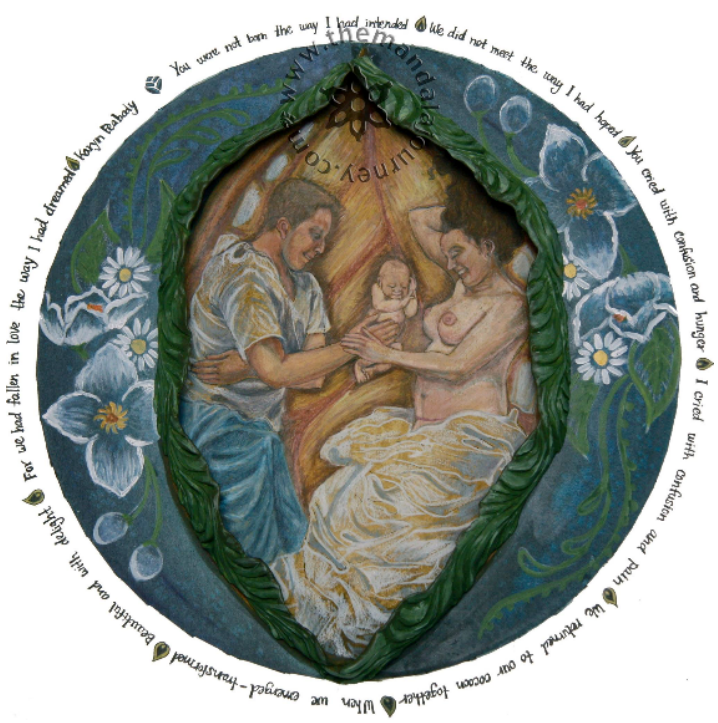

Fonte: https://www.mandalajourney.com/cesarean2 
Porque eu recebi o comentário "pelo menos o seu bebê é saudável" tão frequentemente, tão rapidamente, que eu imediatamente me sequestrei. Eu não queria ouvir aquela... frase. Senti-me inválida. Eu não queria olhar ninguém na cara. Não queria que ninguém visse os meus olhos chocados e aterrorizados e dissesse: "Mas você está viva!" Eu queria e precisava de alguém para dizer: "Você é incrível. Você é tão forte. Você é uma mãe. Obviamente você tem uma resistência e resiliência extraordinárias! "Ou melhor ainda, "Sim, dói. É uma merda que não tenha nascido em casa. Estou aqui para você". Finalmente consegui dizer essas coisas para mim. Fiquei em trabalho de parto em casa por um tempo ridiculamente longo. Eu resisti. Eu tive uma resistência e uma tolerância à dor incrivelmente alta. E então eu fiz a coisa que eu menos queria fazer: fui para o hospital. Eu era corajosa o bastante para deixar alguém me cortar e fazer a cirurgia abdominal ACORDADA! Para que eu pudesse ser sua mãe. Eu sou uma guerreira. ${ }^{8}$

Em contrapartida, "Eu sou uma guerreira" também aparece nos relatos femininos publicados nas redes. Antes de reproduzir um discurso de vitimização já bastante difundido (SARTI, 2010; CARNEIRO, 2015), a mulher é elogiada e admirada por ter suportado viver o indesejado, aquilo que mais lhe casou dor física e emocional e que, portanto, lhe "exigiu muita coragem". Esse é, por vezes, o discurso das mulheres, mas também de profissionais que as acompanharam, doulas, médicos, midwives e parteiras como se pode constatar a partir das palavras de uma outra fotógrafa, autora do projeto Cord $\mathrm{Mama}^{9}$, Monet Moutrie, em um texto intitulado Three Truths About C-section Mamas. Em suas linhas, "c-section mamas are brave", "c-section mamas are strong" e "c-section are beautiful". "Corajosas" por se deixarem cortar em nome de seus filhos; "fortes" por ofertarem cuidados e amor, quando nem se recuperaram de uma cirurgia, e "bonitas" em virtude de carregarem uma cicatriz emocional e física.

\footnotetext{
8 Traduzido pela autora: "Because I got the "at least your baby is healthy" comment so often, so quickly, I immediately sequestered myself. I did not want to hear that...line. I felt invalidated. I did not want to look anyone in the face. I did not want anyone to see my shell-shocked, terrorized eyes and say, 'But you are alive!' I wanted and needed someone to say, 'You are incredible. You are so strong. You are a mother. You obviously have out-of-this-world endurance and resilience!" Or better yet, "Yes, it hurts. It sucks you didn't get to birth at home. I'm here for you.' I finally was able to say those things to myself. I labored at home for a ridiculously long time. I endured. I had stamina and an unbelievably high pain tolerance. And then I did the thing I most didn't want to do: I went to the hospital. I was brave enough to let someone cut me open and have major abdominal surgery AWAKE! so that I could be her mother. I am a warrior" (http:// commonhealth.wbur.org/2015/03/what-to-expect-when-youre-birthing-at-home-a-c-section-possibly). Grifos nossos.
}

9 Saiba mais sobre o projeto acessando: <http://www.cordmama.com/blog/2015/4/8/three-truths-about-csection-mamas $>$. 
Tornar-se mãe deixa cicatrizes em todas nós. Algumas delas são emocionais, outras são físicas. As mães cesariadas (C-sections) frequentemente têm ambas as cicatrizes. E, ainda, suas cicatrizes são lembranças poderosas da força e da coragem que tiveram quando trouxeram seus filhos ao mundo. Essas cicatrizes foram as portas que seus filhos atravessaram quando passaram de um mundo para outro $^{10}$ (CORD, 2015).

Figura 4 - A cicatriz da mãe $e^{11}$

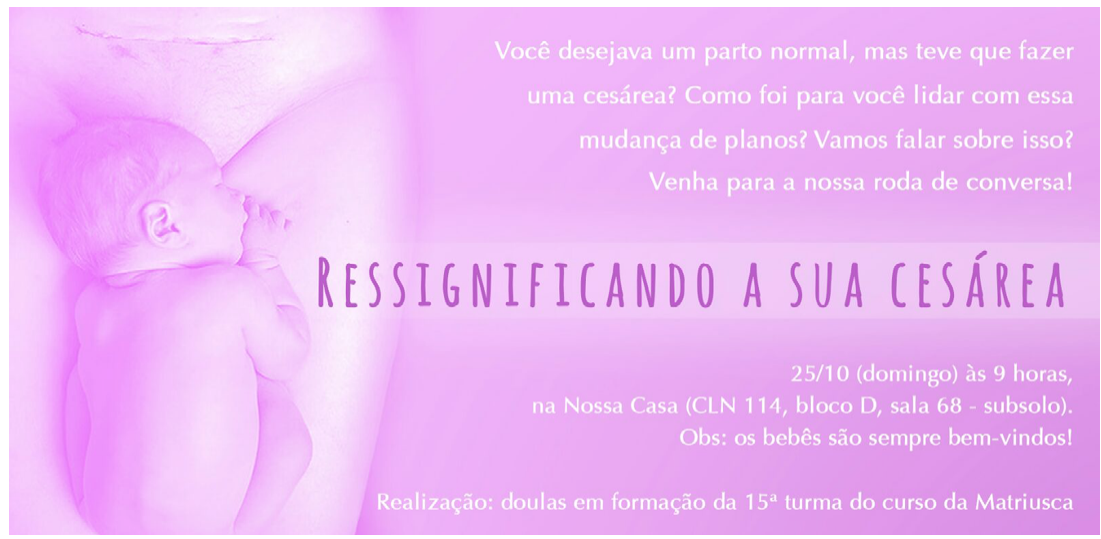

Fonte: https://www.facebook.com/nossacasa711k/?fref=ts ${ }^{12}$

Nesses espaços, a palavra externaliza o corpo e as emoções contidas de tristeza, frustração, raiva, indignação, alegria e gratidão, oscilando entre um polo e outro. Pode-se deparar com mulheres que são gratas à cicatriz, pois trouxeram os seus filhos para a vida. Outras, ainda muito machucadas, que negam a sua existência e sua real necessidade. Pela palavra, as pessoas se conectam, se reconhecem e encontram um lugar para sua fala e para si mesmas. Surge, assim, um novo grupo de mulheres, no interior do ideário do parto humanizado, e estas parecem passar a se reconhecer como pessoa a partir dessa experiência, presencial e virtualmente como bem se observa dos relatos aqui costurados e do que se depreende especificamente da imagem anteriormente referida.

10 Traduzido pela autora: "Becoming a mother leaves all of us with scars. Some of them are emotional, some of them are physical. C-section mamas often have both. And yet their scars are powerful reminders of the strength and bravery they possessed when bringing their children into the world. These scars were the door their children passed through as they left one world for the next."

11 Em sua origem, esta imagem não possui título; o título aqui atribuído se restringe ao papel que ela desempenha neste texto.

12Foto original: http://revistadonna.clicrbs.com.br/lifestyle/foto-de-mae-mostrando-cicatriz-de-cesareae-recem-nascido-divide-opinioes/ 
Demorei um tempo pra olhar pra você mais a fundo. Conhecer seu traçado, sua cor, seu endereço. Era muito doloroso olhar. Passei um tempo te olhando de relance, assim, de vez em quando, às vezes pega de surpresa por um descuido ao passar em frente ao espelho. Na verdade, eu te evitava. Depois que se tornou menos doloroso olhar pra você, resolvi te tocar. Foi esquisito, confesso. Vim com a mão dando toques tão leves que parecia que você se abriria a qualquer momento. Senti sua textura, sua altura. Chorei. Senti um frio na barriga, uma leve agonia. Lembrei que você me acompanharia pelo resto da vida. Não gostei. [...]

Decidi que ao invés de abaixar a cabeça eu vou levantar. A gente vai continuar lidando, uma com a outra, tentando se entender. Mesmo me esfriando a barriga quando olho meu amor maior e penso que poderia ter sido diferente pra ele e pra mim. Mesmo assim. Mesmo voltando no tempo e pensando o que podia mudar, o que podia fazer, o que podia... O que podia, não se pode mais. E a gente vai se entendendo, quem sabe (COLETIVO MATERNAR, 2013 - grifos nossos).

\section{VABC: um novo projeto de vida, foco e determinação}

Vaginal birth after cesarian section é uma expressão que circula bastante no universo das mulheres que queriam um parto natural e vivenciaram uma cesariana. Ou que vivenciaram uma cesárea não questionada anos atrás. Refere-se a uma experiência posterior de parto, um parto natural, considerado humanizado, que acontece depois da cirurgia. Nesse jogo, o "consegui o meu VBAC!" vem atrelado ao "Eu pari!". Parir, então, nesses grupos, aparece como sinônimo de parto vaginal e bem distante da cesárea, que, curiosamente, é muitas vezes nomeada por essas mulheres como o "não parto".

Um VABC, nesse universo, parece ser motivo de comemoração, de brados de satisfação e de orgulho, sentimentos que transbordam nos relatos virtuais e presenciais, pois também acontecem em rodas de conversa sobre parto e pós-parto. Essas mulheres são consideradas corajosas por não se deixaram abater pela premissa médica, muitas vezes repetida, de que "uma vez cesárea, para sempre cesárea" (notas de campo, 2008) - uma ideia que faz a alusão ao perigo da ruptura uterina depois de uma cesárea prévia. Entretanto, mesmo assim, tais mulheres burlam tais recomendações pessimistas e não são nada raros os relatos que enaltecem a recuperação mais rápida do parto vaginal quando comparado à cirurgia.

Mas, igualmente, quanto ao vínculo com o bebê que nasce e com o que já havia nascido meses ou anos anteriormente, pela incisão abdominal. Em minha etnografia nos grupos de parto humanizado paulistas, recordo-me de uma situação em que a mulher dizia ter reestabelecido o vínculo com a primeira filha depois do parto em casa de seu segundo filho. "Nesse parto, nasceram duas crianças e uma mulher". O parto vaginal depois de uma cesariana, então, havia funcionado como um ritual de passagem que firma nascimentos antes "não sentidos". 
Para que se possa ter uma dimensão desse processo que se torna projeto, vale recuperar que, no decorrer de minha pesquisa de campo em São Paulo, anos atrás, havia uma mulher que nem grávida estava, mas já frequentava os grupos de gestantes para preparar-se para um outro parto que não a cesariana frustrante que havia vivido na primeira gestação, quando já se encontrava com $10 \mathrm{~cm}$ de dilatação.

Teve uma hora em que ele [médico] me perguntou: "nossa, não sei porque você está chorando tanto, parece até que é sua primeira cesariana”. Minha filha passou por todos os procedimentos desnecessários que fazem de rotina com o recém-nascido e foi para o berçário. Ela ainda nasceu pequena para a idade gestacional, então, provavelmente, nasceu antes do tempo.

Me senti péssima. No fundo, eu sabia que não era necessário, que ele estava me enganando, mas não via uma saída para fugir daquilo ali. Não me senti nem coadjuvante, me senti o cocô do cavalo do bandido. Depois da segunda gestação, decidi me formar doula para poder ajudar outras mulheres a não passarem pelo que passei (ANJOS, 2015b).

A dor e os sentimentos de fracasso e frustração funcionam, portanto, como mola propulsora para o VABC. As mulheres passam a se informar e a ter outros profissionais na assistência para não repetir o vivido, para sentir com o corpo e no corpo o que imaginam ser o parir.

Para mim era o momento mais importante da minha vida, mas lembro de mim deitada naquela mesa fria, com aquela máscara enorme no rosto, corpo imóvel, lágrimas rolando e por dentro eu só pensava: "o que estou fazendo aqui? Não era pra ser assim, não foi assim que eu sonhei conhecer meu filho." Para o meu azar, a anestesia não pegou na primeira vez e teve que aplicar outra. Aí, com a demora entre a primeira (que absorvi grande parte) e abrir e tirar, meu filho acabou absorvendo uma parte e nasceu com desconforto respiratório, ficou duas longas horas longe de mim, e não amamentei na primeira hora (notas de campo, 2008-2010).

O VABC torna-se, assim, projeto. Um evento que quando alcançado vem na ordem do extraordinário, de um acontecimento que rompe o cotidiano e ressignifica a dor e o sofrimento anteriores. Mas, para além dele, parece existir também uma reelaboração feminina diária do acontecido, uma relação com o tempo constante e com o que existe de ordinário no cotidiano. Tais mulheres, como a que se viu no diálogo com a própria cicatriz, tomam contato diariamente com suas marcas da cesárea indesejada ao abrir ou fechar uma calça; quando se relacionam com seus filhos; cuidando-os, cuidando do corpo que se reestabalece da cirurgia indesejada; quando entraram em grupos que versam sobre o assunto; quando expõem a sua dor ou passam a trabalhar com assistência ao parto com o intuito de transformar algo do sistema de cuidado atual; quando fazem sexo depois da cirurgia ou quando trocam de roupa em espaços públicos, como a piscina, o clube ou a praia.

Essas mulheres, antes de perseguirem o extraordinário, o parto natural depois da cesárea, fazem do ordinário, do dia a dia, o seu espaço de fala, uma fala 
que pode ser inclusive silêncio, na esteira do que Pereira (2010) aponta sobre a obra de Venna Das, mais especificamente, sobre o seu modo de fazer etnografia, a saber, acompanhando o tempo e o ordinário, os afazeres que as mulheres empreendem e que subvertem ou tratam de suas violências, traumas e dores. Essas práticas, ao final, significam a vida e conectam temporalidades e processos subjetivos que desenham pessoas. Dessa forma, no manejo do cotidiano e do presente, alinham o passado e constroem uma trajetória que passa a fazer sentido.

Por tudo isso, penso que uma etnografia sobre esse cotidiano, o de mulheres que vivenciaram uma cesárea indesejada, é de grande importância para a compreensão desses processos e da interface entre o feminino, a domesticidade, o corpo e as possibilidades de reinvenção de si (DAS, 2011).

\section{A título de conclusão}

Sem poder nada concluir, um ponto de costura entre todos os pontos trabalhados nesse artigo parece ser a ideia e a prática de corpo/corporalidade envolvidos nesses processos. Esses corpos que portam a cicatriz são ditos e dizem de si mesmos. Nesse jogo, o corpo, portanto, atua como "produtor de sentido" e aparece "dotado de agência própria" (MALUF, 2001, p. 89), moldando mais existências depois da incisão do que sendo moldado ou simplesmente impresso pela cultura.

$\mathrm{Vi}$ como essas mulheres passaram a viver subjetivamente marcadas pela cirurgia e como essa experiência corporal (ou não experiência) contornou percepções de saberes e de fazeres, propiciando espaço para a reflexão sobre a cultura em geral: saberes obstétricos, leituras de corpo e de feminino. Desse modo, é o corpo quem me permite ler e refletir sobre a cultura. Desta feita, antes de ser o corpo algo que recebe impressões sociais, me diz do cotidiano, das crenças, das emoções e dos valores sociais operantes. $O$ interessante é que se o fazem com relação à cultura biomédica, acabam por fazê-lo também com relação ao próprio ideário do parto humanizado, haja vista pautarem a impossibilidade do parto mais natural, ainda que muito desejado, em muitos casos e situações, por uma gama de razões. Nesse sentido, tais corpos cortados funcionam como uma dobra ou mecanismo de compreensão da cultura contemporânea sobre as ideias de parto, nascimento e corporalidade feminina. Sugerindo-nos que o parto mais natural também pode tornar-se regra de ouro a ser buscada e, assim, excluir e isolar mulheres a partir de seus corpos e de suas experiências de parto.

No âmbito pessoal, esses corpos relatam dor e sofrimento e, assim, subvertem a relação das mulheres com o próprio corpo e consigo mesmas, impondo uma subjetividade que advém do corpo cortado, algo que dele brota e que não mais aparece como consequência social. Ao falarem sobre os seus corpos e marcas, essas mulheres falam de si mesmas como pessoas - desencontradas, externas a um grupo, isoladas e, por vezes, tidas como fracassadas ou falhas. De algum modo, algumas passam a se reconhecer como mulheres que perseguem um VABC. Outras como as que se envolverão com a temática do parto também profissionalmente como doulas, por exemplo, fazendo do pessoal algo público. 
Se avento tal possibilidade de leitura é para ao final refletirmos sobre a proficuidade de trabalharmos com a ideia de embodiment e de corpo como a base existencial da cultura. Nos dizeres de Maluf (2001, p. 96):

As implicações do embodiment, não apenas como forma de abordar o corpo na cultura, mas sobretudo como um novo paradigma teórico e metodológico para a antropologia são muitas: 1) o corpo não é mais um fato bruto da natureza nem um fato dado - nem para nós mesmos; 2) a objetificação do corpo é um processo construído histórica e culturalmente - e um segundo momento da experiência da percepção; 3) o corpo é sujeito e agente da/na cultura; 4) a cultura é corporificada (embodied) e não dada exteriormente à experiência do sujeito; 5) o outro também não é percebido como objeto, e sim como um "outro eu mesmo"; e por fim 6) a "objetividade não é a visão de nenhum lugar, mas uma visão de qualquer lugar onde o corpo possa tomar posição" e se colocar em relação às perspectivas de outros "eu mesmos".

Diante disso, a vivência de uma cesárea indesejada, os relatos e as práticas que essa experiência tem ensejado na atualidade, nos abrem brechas para pensar sobre a centralidade do corpo, de suas marcas e de sua relação com a noção de pessoa, descontruindo leituras naturalizantes. Se, evidentemente, a baliza for o processo de não objetificação.

\section{Referências}

ALAYA: blog. Relatos de parto. 2013. Disponível em: <http://alaya77.blogspot.com.br/p/relatos-de-parto. html>. Acesso em: 26 dez. 2016.

ALVAREZ-ERRECALDE, Ana. Cesárea, mas allá de la herida. Barcelona: Ed. Obstare, 2009.

ANJOS, Anna Beatriz. As vozes caladas pela cultura das cesáreas. Revista Fórum, 30 jan. 2015a. Disponível em: <http://www.revistaforum.com.br/2015/01/30/as-vozes-caladas-pela-cultura-da-cesarea/>. Acesso em: 26 dez. 2016.

As histórias de dor e superação de mulheres submetidas a cesáreas indesejadas. Pragmatismo Político, 14 fev. 2015b. Disponível em: <http://www.pragmatismopolitico.com.br/2015/02/historias-dedor-e-superacao-de-mulheres-submetidas-cesareas-indesejadas.html>. Acesso em: 26 dez. 2016.

CARNEIRO, Rosamaria. Cenas de parto e políticas do corpo. Rio de Janeiro: Fiocruz, 2015.

COLETIVO MATERNAR: blog. A cicatriz. 19 mar. 2013. Disponível em: <http://coletivomaternar. blogspot.com.br/2013/03/a-cicatriz.html>. Acesso em: 26 dez. 2016.

CORD. Three Truths About C-section Mamas. 10 abr. 2015. Disponível em: <http://www.cordmama.com/ blog/2015/4/8/three-truths-about-c-section-mamas>. Acesso em: 26 dez. 2016.

CSORDAS, Thomas. Corpo, significado e cura. Porto Alegre: Editora UFRGS, 2008.

DAS, Veena. Life and words: violence and the descent into the ordinary. California: University of California Press, 2007.

O ato de testemunhar: violência, gênero e subjetividade. Cadernos Pagu, n. 37, p. 9-41, jul./dez. 2011.

LOWE, Ananda. What to expect when you're birthing at home: a hospital c-section (possibly). 20 mar. 2015. Disponível em: http://www.wbur.org/commonhealth/2015/03/20/what-to-expect-when-yourebirthing-at-home-a-c-section-possibly>. Acesso em: 05/02/2016. 
MALUF, Sonia. Corpo e corporalidade nas teorias antropológicas. Esboços Dossiê Corpo e Historia, v. 9, n. 9, p. 87-101, 2001.

PEREIRA, Pedro Paulo. Violência, gênero e cotidiano: o trabalho de Venna Das. Cadernos Pagu, n. 35, p. 357-369, jul./dez. 2010.

SARTI, Cinthya. Corpo, violência e saúde: a produção da vítima. Sexualidad, Salud y Sociedad. Rio de Janeiro, n.1, p. 89-103, 2009.

WAGNER, Roy. A invenção da cultura. São Paulo: Cosac \& Naify, 2010.

Recebido em 15/10/2017

Aceito em 09/02/2018 